\title{
Narratives of transactional sex on a university campus
}

\author{
Tamara Shefer ${ }^{\mathrm{a}} *$, Lindsay Clowes $^{\mathrm{a}}$ and Tania \\ Vergnani $^{\mathrm{b}}$ \\ aWomen's and Gender Studies, University of the Western Cape, South Africa;

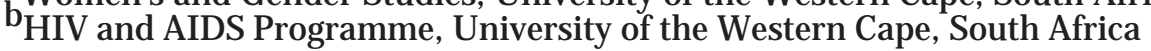

Given the imperatives of HIV and gender equality, South African researchers have foregrounded transactional sex as a common practice that contributes to unsafe and inequitable sexual practices. This paper presents findings from a qualitative study with a group of students at a South African university, drawing on narratives that speak to the dynamics of reportedly widespread transactional sex on campus. Since many of these relationships are inscribed within unequal power dynamics across the urban-rural and local- 'foreigner' divides, and across differences of wealth, age and status that intersect with gender in multiple, complex ways, it is argued that these may be exacerbating unsafe and coercive sexual practices among this group of young people. The paper further argues for a critical, reflexive position on transactional sex, pointing to the way in which participants articulate a binaristic response to transactional relationships that simultaneously serves to reproduce a silencing of a discourse on female sexual desires, alongside a simplistic and deterministic picture of masculinity underpinned by the male sexual drive discourse.

Keywords: transactional sex; HIV/AIDS; university; gender; South Africa

\section{Introduction}

While initially concerns about transactional sex and HIV focused on sex workers as a particular 'risk' group in efforts to understand the rapid progress of heterosexual infections in Southern Africa (Gould and Fick 2008; Varga 1997), there has been increasing concern with transactional sex more broadly in heterosexual relationships. Transactional sexual relationships, especially where age and material difference are marked, are increasingly an area of concern in addressing HIV transmission as well as gender-based violence in Southern Africa.

The latest National HIV Prevalence, Incidence, Behaviour and Communication Survey conducted by the HSRC (Shisana et al. 
2009) identified sex between young women with older men ('sugar daddies') as a significant risk factor for young women with respect to HIV infection. Moreover, the percentage of women with sexual partners more than five years older than them increased from $18.5 \%$ in 2005 to $27.6 \%$ in 2008. This increase arguably highlights the unequal status of particularly young, poor women and how this may facilitate their exposure to unequal, exploitative relationships and unsafe sexual practices. The link between sex, gender and money is clearly significant in a society where, in 2003, men took home almost two thirds of the total income (Casale and Posel 2005).

There has been a growing focus on transactional sex as playing a role in unsafe sexual practices in the Southern African region (Clowes et al. 2009; Dunkle et al. 2004, 2007; Gukurume 2011; Leclerc-Madlala 2004; Maganja et al. 2007; Masvawure 2010a, 2010b; Oxlund 2009; Ulin 1992). That transactional sexual interactions are embedded in notions of gender, love and exchange in local contexts has also been illustrated and assumptions of transactional sex as necessarily based on poverty, and in which women and girls are victims and men active agents, has also been problematised (Hunter 2002, 2010). For example, Bhana and Pattman's (2011) recent study with a group of poor, young women in a township in KwaZulu-Natal showed how ideals of love amongst participants were bound up with aspirations for material goods. Similarly, some argue against a simplistic analysis of transactional sex in which those providing the sex are necessarily victims (see Masvawure 2010b; Oxlund 2009). At a larger international level it also needs to be remembered that exchange of sex for material goods or other gains is universal and embedded in normative heterosexual relationships, especially in a consumerist, materialist global context. Thus the assumption that materiality is bound up with notions of love only in African contexts may reflect a northern 'othering' and racist discourse on African sexuality that has been highlighted by researchers deconstructing popular and academic discourses on HIV and AIDS (for example, Jungar and Oinas 2004; Patton 1990; Seidel 1993). Indeed the notion that marriage and normative heterosexual relationships reflect a form of transactional sex is not new to feminist critiques of patriarchal society (see de Beauvoir 1982; Cronan 1973; Okin 1989).

Around the world, university campuses are constructed as spaces of sexual exploration (Adam and Mutongi 2007; Ergene et al. 2005; Page, Hammermeister, and Scanlon 2000; Seloilwe 2005). A number of studies at university campuses have further illustrated the salience of transactional relationships for the purposes of status and material gain (including access to clothes, cell phones, driving in smart cars, wearing fashionable clothes and so on). These have also foregrounded the resilience of heteronormative gender inequalities in 
contemporary relationships (Clowes et al. 2009; Gukurume 2011; Masvawure 2010a, 2010b; Shefer and Foster 2009). In the light of this work, and since there is concern about the HIV status of young people at universities and practices of coencive sex and gender-based violence, it is important to gain further insight into the particular understandings and reported dynamics of transactional sexual relationships at South African universities.

\section{The study}

This paper is based on data collected through a study that aimed to explore a group of students' perceptions of practices of (hetero)sexuality on and off campus. Aiming to inform interventions for challenging inequitable and risky sexual practices in ways that are appropriate to students' particular contexts and needs, a particular focus was on reported unsafe sexual practices and the conditions facilitating these unsafe practices. Within this broad aim, the study was concerned to document reported sexual practices on campus, in particular the extent to which students felt they were able to practise safe and equitable sexual relationships and what the perceived challenges to this are. The study was clearly focused on the power relations and inequalities expressed through the normative gender roles permeating heterosexual relationships on campus.

A feminist qualitative methodology including a sensitivity to gender differences at all phases of the research process as well as employing methods of self-reflexivity with respect to the position and subjectivity of the researcher and fieldworkers was utilised (see, for example, Hesse-Biber 2007; Ramazanoglu and Holland 2002). All standard ethical procedures were maintained, with particular sensitivity to issues of confidentiality and anonymity, given the focus on sexualities and the link with HIV (still highly stigmatised in most communities in South Africa). Through a convenience sampling method, male and female students at an English-medium historically Black university ${ }^{1}$ were recruited across all levels from first year to postgraduate to participate in focus group discussions. Guided by a semi-structured interview guide that asked questions about the nature and dynamics of sexual relationships between men and women on campus, with a particular focus on challenges to safe and equitable sexual practices, a total of 20 focus groups were facilitated. The interview schedule included open-ended questions about practices of sexuality on campus and included one item about transactional sex, which asked if participants felt this was a feature of campus relationships. Notably, focus groups frequently reflected on transactional sex before the item was asked.

Participants were recruited in advance through existing class-based forums, such as practical groups and lectures, with only students 
above the age of 18 years included in the study. Focus groups included between 6 and 10 participants each, with a demographic questionnaire administered at the start of each discussion for purposes of description of the sample. While some were mixed (10 focus groups), other groups comprised only male (5 focus groups) and only female students (5 focus groups). An attempt was made to stratify the sample across age, gender, language, 'race', class and culture as well as South African and students from other countries. Both students living on campus (in residence) and off campus were recruited. Bearing in mind the nature of qualitative methodology, while the sample was not representative of the full body of the target population, a diversity of representation was achieved.

Skilled facilitators, acceptable and appropriate with respect to age, gender and cultural/language background, facilitated each group. To minimise the possibility that students might feel interrogated about their own sexuality, facilitators framed questions as a discussion about campus life in general, enabling students to respond in the third person. Thus, mostly participants spoke of 'others' rather than sharing personal narratives.

Discussions lasting between 1 and 1.5 hours were largely conducted in English and were audio recorded with permission of participants. Once the discussions were transcribed, a qualitative thematic analysis, informed by a discourse analytic reading, was conducted on the transcripts, which were transcribed verbatim from the audio recordings. A computer analytical package, AtlasTI, was utilised to assist in processing and analysing the data.

\section{Discussion of the findings}

One of the key findings of the overall study was that transactional relationships between men and women were reported as common on campus. In drawing on this corpus of data, this paper explores participants' perceptions and reported understandings of the dynamics of transactional relationships as they occur on this campus. It should be noted that at all points we are dealing with the terrain of the discursive - we have no access here to actual practices but rather a group of students' constructions of such practices that are informed by dominant and/or resistant/alternative discourses on transactional sex. The analysis presented here elaborates on the ways in which transactional relationships are represented by participants as exchanges built around a variety of currencies. As we discuss below, while money and financial need is seen as important, exchanges hinging around other forms of benefits linked to the particular campus context are also commonly reported. We reflect also on silences and marginalised discourses that are implicit in the dominant way in which transactional sex is presented by participants and that link to larger debates on transactional sex in the literature. 


\section{Material exchanges}

In talking about sex on campus, participants indicated that an expectation of sexual intimacy following a material exchange was normative. Such a discourse generally assumed men as in the provider role with women positioned as those who could offer sex, as in the narrative below:

I think the typical sexual encounter on campus is mainly amongst res students on a Friday or a Saturday night. They go to The Barn, you meet some guy and he asks you typically if you're a 1st year or a 2nd year. These guys come to you, introduce themselves, buy you a drink, you're on the dance floor at The Barn etc. ... Then at 3 o'clock when it closes and he assumes then 'cos [because] after about two hours when he's danced with you and bought you a drink then he assumes the typical thing is he thinks so now we can go to my room. ... And that's how it happens. (Natasha, 21 years, mixed-gender group)

According to participants, sugar daddies or 'ministers of finance' are a common phenomenon on campus with not only richer male students acting as sugar daddies but also working men from off campus who visit campus to find sexual partners. These were almost always represented as heterosexual interactions, with no mention of such interactions between women and only one between men as in the example below:

In order to buy money, to have money for photocopies and things like that. ... I heard of guys having sex with other guys for money ... because they, they don't have food. (Donovan, 26 years, men group)

For the most part, transactional sexual interactions were represented as involving female students having sex with (usually older) male students or men from off campus for material gain, although there was one report of a female student perceived to be a 'sugar mommy'. Material exchanges were reported to be primarily in the form of money or food or 'stuff' that is needed:

And the problem is that, most people, and girls from campus, they tend to, sort of not sell themselves, but sell themselves because, I mean, they're living on res, they need stuff. And I've been seeing this tendency of having, you know, sugardaddies. (Nosipho, 22 years, women group)

Especially females who live on res, they have transactional sex, they do it for money. And there's also this phenomenon where they speak about 'friends with benefits'. (Charlene, 19 years, women group)

And then, some of the other girls that I know, they were from, uhm, KwaZulu Natal and from the Eastern Cape, and they don't 
have money, but they have this Nigerian boyfriend, who they have the boyfriend that's working. And now, they uhm, invite the guys come for a weekend, you must buy food, for that food and the money, I will giveyou sex. (J anet, 20 years, women group)

Participants also referred to how more than one sugar daddy at a time was not considered unusual and, in fact, had advantages since this would increase the monetary benefits accruing to individual female students:

Ja, I understand, but the poverty that we are talking about, this allows some girls to get more money out of them. You see what I mean? And once you've got five of them, they give you R500 times five. (Thandi, 22, mixed-gender group)

That some women students were perceived to be dependent on these relationships and that they may be abusive was evident through the claim that women students would even tolerate physical abuse for fear of losing such material benefits:

I, I, I might be with a guy who hits me all the time, and I just want to be with him because of what you're saying, because of his car. (Nyameka, 21, mixed-gender group)

Participants constructed transactional sex as a deliberate strategy on the part of some women to draw older employed men with disposable incomes into relationships with them. This is then viewed as setting up the campus as a 'resource' for off-campus resourced men:

Especially on res, this new thing of having sugar daddies, and having rich men, actually taking care of them. And, that's, they go out to town to actually go get this, these men. And then later on, they would be, they would like [write] them their love, so the men would call them, and like, 'oh ja', they like, 'I'm a student' and all that stuff. 'I don't have money to come to you'. So that's the first transaction. They get money, to find out, do you have the money. (Sean, 19 years, mixed-gender group)

I know a guy who lives in Elsies now he decides to come here on weekends to Condom Square. He's got a car so he can go anywhere but he decides to come here so he's from Riversdal - his residence is $10 \mathrm{~km}$ down the road, but he comes here to party. (Sipho, 22 years, mixed gender group)

Ok I don't know if it's just me, but I've noticed a lot of smart cars pull up here round about like after work, and then these young students, girls get into these smart cars, or guys get out of the cars [go to the movies] or whatever. So, I don't know if it's true, but I have a feeling there were a lot of sugar daddies, they coming in from work, and, going for young girls. (Zayaan, 19 
The intersection of age and financial means is further perceived to encourage young female students to engage in transactional relationships. Those, such as first-year students, who are new to the 'freedom' of campus sociability, as well as from less urban and less well-resourced environments, are perceived as those more likely to engage intransactional sex. Participants argue that such students are often more trusting and naive and more easily impressed by the proximity to resources not readily available in their home contexts. Older male students are reportedly aware of such dynamics and are believed to exploit these as articulated by a male student about his peers in second year:

Like we're all second year now, and, they like made a point of going to orientation, to like meet the first years and get into the 'Freshers' Braai', and things like that. (Owen, 19 years, mixed-gender group)

Participants articulated the perspective that first-year, female students in particular may be vulnerable to engaging in nonequitable transactional relationships since they arrive on campus as 'strangers' to these contexts and may depend on such transactional relationships to achieve a sense of belonging and confidence:

Yes, you'll see at the beginning of the year now, 1st years, these kids come, they're vulnerable. A lot of seniors and people from off campus and the seniors are like lions they come to our residences. And you know you feel flattered, like oh he likes me, I'm gonna have a boyfriend. Then they go into it for a short-term relationship. And not knowing that this guy's got a steady girlfriend ... . he's been here for ages and done this before. And so they use the girls. (Zulfa, 23 years, mixedgender group)

I think the 1st years are vulnerable. Big cars, nice cars looking for ladies. They can't handle the freedom. Mom and daddy don't know. They don't even have a curfew. They sent you to varsity to study so if you arrive home at 2am before a tutorial, whose going to know? (Thabisile, 19 years, women group)

Come I tell you like, see on, when you live on res, right, your parents are not here, and whatever. And, okay, some people's uhm, mothers' keep them, you know, keep them in a little hokkie [shed] or whatever. And then they come here, they're https://repository.uwc.ac.za/ 
'Ooh', so open and whatever. And then they have that freedom and stuff like that. (Susan, 19 years, mixed-gender group)

\section{Alternative resources for transaction}

While narrow economic motivations - cash or food and other material goods - are foregrounded by students interviewed, as above, a wide range of other resources also emerged as salient in sexual interactions that were described as transactional by participants. Thus, while students emphasized the ways in which sex could be used to accrue material benefits and supplement limited or inadequate nutritional resources, they also talked about the ways in which there were alternative forms of currency. There was a strong sense, as we discuss below, that women (and men) engage in transactional sex on campus for the social status and other benefits it can deliver.

Participants argued that it was the appearance of being monied that seemed important rather than money itself. Thus cars, and other material accessories that testified to a man's affluence, were viewed as important in facilitating sexual relationships:

It doesn't matter you can look like Shrek but if you have a car you'll get a girl, it doesn't have to be your car or your money, but as long as you have it in your possession you'll get the girl. (Melanie, 24 years, mixed-gender group)

And also most of the students in our age group that have cars .. . mm ... they park their cars outside the student centre and they play loud music and while all that is going on playing soccer and some are smoking ukupipe and while all this is going on some of them are doing it in the cars. I know this 'cos [because] in 1st year my best friend was a Moslem and I was introduced to the culture of the best thing is get a car ... where you have a friend with a car and then this is what you do. (Susan, 23 years, mixed-gender group)

Other non-material resources salient in the university context are also viewed as underpinning transactional sex. Older male students who did not have either cars or cash, for example, were reportedly able to draw on their familiarity with and seniority within the institutional structures that conferred power and status on campus. Access to students in positions of leadership, such as members of the Student Representative Council (SRC) and the resources that accompany that position were apparently desirable commodities that could be traded with women for sex:

Some of them they use their portfolios from within the university, no I'm on the SRC, I'm a this on the law student council, I drive the Venture for the SRC, some power, some position that's how they get it. (J enny, 25 years, mixed-gender group) 
... guys that like [in] third year, you know, fifth year or whatever, so for them they have the upper hand. They very smooth, they know a lot of people which kinda make them seem cool [agreement]. So the girl thinks, if she did something with them, automatically they will also be in the 'In crowd'. And that's a lot of pressure and stuff. Even if he can just, 'Oh, come we go for a walk or whatever,' you know, take a walk from the caf [student restaurant] to the A block [campus building] or whatever, that's a long trip, where a lot of words can be exchanged ... (Fatima, 19 years, women group)

I just want to go back to what [participant] said about us girls being materialistic, because I can see at residence when you come from your home you used to, I don't want to say a primitive life, but you used to whatever, not very materialistic and now you come here and you meet people who come from very well-off homes and they dress up and everything and you also want to fit in and everything and that's why they date older men, date guys with cars. They know they can get cash; they can buy clothes because there's poverty at residence. You live on bread and peanut butter. (Melissa, 25 years, mixedgender group)

Some students reported that it was not uncommon for sex to be exchanged for assistance with academic work. Participants suggested that post-graduate male students could help with assignments and even write theses in exchange for sex. In the narrative below, such a transaction is also overlaid by the notion of 'international students', that is, those who are not South African nationals. Linked to a social location marked 'foreign', international students apparently have a reputation for strong academic work, which can be drawn upon by South African women to bolster their own academic results. In the narrative below, the participant explains how because non-South African students are under pressure to complete their degrees in a short time, given work permits and bursaries, and therefore work very hard, they may be viewed as academic resources. While this practice may be happening the other way around, with women completing assignments for their male partners, international women students specifically highlighted how international male students were those targeted as a resource by local women students:

... they know the guy will work very hard on their assignment, two assignments, his and hers, and he knows in return he will get sex. And instead of her failing, she will rather sleep with him and get her assignment done. ... I've heard men who are married back home ... . who have girlfriends here and their relationship is based on their work ... (Assumpta, 28 years, mixed-gender group) 
According to participants, perceived benefits for non-South African male students also go beyond the sexual, since such relationships may provide some measure of protection in the current local climate where hostility to 'foreigners' has emerged as a challenge in contemporary South African contexts:

The same thing that is happening outside the university, it happens at this institution where some males feel that associating themselves with a South African student will give more privileges actually, you know, and more protection actually. (Yvette, 27years, mixed-gender group)

Indeed, where non-South African national students are exposed to psychological and physical abuse as evident in recent xenophobic attacks (see Crush and Pendleton 2004; Valji 1993), relationships with South Africans (of either sex) may offer some measure of physical and emotional security. The apparent advantages of association with a South African, privileged by their citizenship and familiarity with local resources, further highlights the contextual and local framework that shapes sexual relations and what are viewed as transactional relationships on campus.

\section{Binarisms and silences}

Markedly absent in these discussions is any substantive acknowledgement, either by male or female participants, of female sexual pleasure or enjoyment of sexuality. A discourse on female sexuality and desire was, instead, conspicuous more by its absence from any discussion around transactional sex. Participants overwhelmingly set up a binary, either sex for love/relationship or sex for money and/or other benefits, with female students in particular attempting to guard against being inadvertently placed in the 'wrong' one through their narratives:

I think cars play a big role in that. I'm not saying all girls are materialistic and that but you'll see girls that don't know a guy but if the guy's got a nice car she'll like walk up to him and flirt and stuff. Which is not cool to see a girl doing that 'cos [because] it misrepresents the rest of us who are not like that but its reality. (Nokuthula, 19 years, women group)

At the same time, however, students also attempted to think more critically about these dualisms. Both male and female students spoke, for example, about how the boundaries are seldom clear between transactional sexual relationships (generally set up as casual encounters) and what are considered as normative longerterm relationships:

But sugar daddies you know there's a conception that there's a much older man the money and sex thing. But these guys there's actually a relationship. But they're not even providing food and clothes they just provide a lifestyle. That's how it 
started out. 'Cos [because] you could get her into a club, buy her drinks but now it's a relationship. (Vuyo, 23 years, men group)

Yah, like he will have the money to take her out and stuff, but she doesn't necessarily solicit it, you know what I mean? So it's sort of there. (Carol, 22 years, mixed-gender group)

Participants appear to find it challenging to negotiate this binary. On the one hand, they can see it is problematic to see transactional relationships as separate to 'normal' heterosexual relationships, on the other, hegemonic discourses around sex for love versus sex for money (and other material benefits) structure thinking in particular ways:

I think in society in general you know relationships have become transactional because of materialism ... I know of people which then 'if you can't do this for me then I can't be in a relationship with you'. (Janine, 26 years, mixed-gender group)

Inherent in this binarism is the overriding picture of women students as divided between those who have sex for love or for money/goods/other benefits. There is little acknowledgement that women might desire sex for pleasure or for fun (and perhaps enjoy material and other benefits as well) evident in the students' narratives. Yet at the same time there were a very few female voices and no male voices acknowledging female desire as positive, even if it was not well represented in the larger corpus of texts:

Well, honestly on my whole perspective of today, girls are more sexually out there. They're more sexually active. They're sexually intellectual. They're not shy. So, like, yesteryear, like years ago, girls wouldn't actually, like how can say, it will be like taboo for girls to talk about sex, to even say like, 'I had sex'. (Zodwa, 22 years, mixed-gender group)

I don't think most people that have one night stands are always drunk. I know of a friend and she enjoys having sex with different people. She says it's nice having 'different kinds of flavours'. So I think it's not necessary a thing with drinking. Yes drinking does make it easier. It allows a certain justification for your actions - 'oh I was drunk, I was wasted'. But there are those who just have sex because it's recreational, it's healthy. (Desiree, 26 years, mixed- gender group)

I ... don't think it's fair to say that women invite men to have sex with them because of the way they dress or whatever. It is assuming that women don't actually have sexual feelings. They do They do have sexual feelings. We assume that it's 
only men who have sexual feelings and they can't resist. Women do. But I think it's the power dynamics which exist between men and women and because you can then give me something and because of the culture, a woman can't ask. We've been taught a woman can't ask, even if you feel like, you won't ask, you won't make the first step. So that's something that just came to my mind. I think it is really important because it is happening. (Assumpta, 28 years, mixed-gender group)

The other side of the coin of the dominant construction of women as focused on material goods when engaged in transactional relationships was the dominance of the picture of men being focused on the sex part of the transaction. Apart from the observation that 'foreign' men might find security in relationships with South African women, little or no attempt was made by either male or female students to think critically about why men might engage in transactional sex. Instead this was taken for granted as self-evident, as not requiring explanation. Indeed the academic literature itself may be viewed as assuming a one-dimensional picture of men's investments in transactional sex that may not acknowledge the complexity of men's sexualities and challenges with respect to achieving hegemonic masculinity. This male sexual drive discourse has been well documented as central to understandings of male sexuality in South African contexts (Lindegger and Maxwell 2007; Ratele 2006; Shefer et al. 2005; Shefer and Foster 2009). And yet there were hints in some of the discussions that men's motivations are more complex and multi- dimensional:

On campus it becomes more of a problem. Off campus there are less restrictions maybe but it's the same things. It works the same. I have a cousin here on residence. He's a guy and he was just telling me how many girls he's met and who he wants to have sex with and he wasn't like that at home. You get here and it's a different culture. He thinks everyone's having sex but him. He feels his pressure, he needs new sneakers, he also feels that pressure to look a certain way to dress a certain way to attract a girl, to fit in. His friends think he's odd because he hasn't had sex yet, he's been here two months and he hasn't had sex yet. (Desiree, 26 years, mixed-gender group)

... they [men] won't only just go to a sober girl like and hit on her and within a matter of like five seconds and they're in bed already; they would go for those that obviously have been intoxicated and I guess for the men they feel that they ... [are] powerful and that's it! But they not really powerful because those people are drunk, you know what I mean? (Andile, 19 years, men group) 


\section{Conclusion}

In sum, both male and female students' narratives for the most part foregrounded transactional sexual interactions on campus as hinging around class and gender. Focusing on women's reduced access to economic resources or unmet material desires, this discourse hinges around the economic vulnerability of young women, presenting poverty as the key reason for women students engaging in transactional sexual interactions. Men, in contrast, are positioned as economically privileged (or performing as such), a discourse in which successful masculinity is premised on access to and control over economic resources, a version of masculinity described by Hunter (2009) as 'provider masculinity'. Transactional sex, while believed to be inevitable and even glamorous (evidenced in the somewhat grand title of minister of finance), is also 'othered' by participants and framed in a moralisticlens. This contrasts with other studies on the continent, such as that by Wamoyi et al. (2010), who reported that transactional sex was not perceived as immoral among their participants in a rural community in North Western Tanzania. In this respect, the study may point to the impact of middle-class, urbanised values and highlights the binarism of 'respectable' versus 'bad' femininity, which casts a judgemental frame over practices of transactional sex. For women in particular this binarism appears to overlap with the whore- madonna trope that has been highlighted as salient in the South African context, as it has internationally, and reframed by notions of 'clean' and 'unclean' women in discourses on (un)safe sex (for example, Shefer and Foster 2009; Waldby, Kippax, and Crawford 1993; Wood and Foster 1995). Missing from this discourse is any substantive positive narrative on female sexuality and desire, and this has also been identified as a challenge in the broader context of heterosexuality studies (Holland et al. 1991; Lesch and Kruger 2004; Shefer and Foster 2009). In other words, in emerging out of particular social, historical and cultural contexts in which female sexuality in general (and female transactional sex in particular) is constructed negatively, these students are (not unexpectedly) reinscribing dominant discourses around heterosexuality and gender that deny the possibility of any transactional relationship being equitable or non-exploitative.

At the same time, however, and reinforcing the findings of Masvawure (2010a), there are clear signs in participants' narratives that transactional sexual encounters on campus are not simply about money but also involve a range of material and emotional transactions that can confer benefits on both men and women. Women are not necessarily passive victims in these exchanges, they may actively and strategically engage in such relationships as has been argued by Gukurume (2011) in his study on a higher education campus in Zimbabwe. And at the same time, there are hints that a few 
female students are aware that women also have sexual feelings and can experience sexual desire, although they also recognise that it is risky to acknowledge this publically. It is especially noteworthy that students' narratives highlight a continuum of relationships in which the boundaries between a transactional relationship and a 'normal' intimate relationship are not clear. What becomes more important is to differentiate between relationships that are equitably transactional and those that involve intersecting axes of power that facilitate possibilities for exploitation and abuse of either partner.

It is also evident that men's involvement in transactional relationships needs to be explored more deeply. Overall, both male and female student narratives around men and transactional sex are circumscribed by a framing of masculinity and male sexuality within the dominant male sexual drive discourse (coined by Hollway 1989), reproducing a simplistic and deterministic picture of masculinity and sexuality. And yet here, too, there are signs that things are more complex, with a few students acknowledging that men's transactional sexual relationships with female students can be closely connected to men's expectations of other men, for affirmation from peers, for intangible goods such as safety and security as well as material benefits such as a bed and shelter.

In conclusion, we suggest that there is a need to approach transactional sexuality with a more critical and nuanced lens. The assumption that intimate heterosexual relationships built around material exchanges are only legitimate if preceded by vows of marriage needs to be considered more critically. As noted by Cronan (1973) almost four decades ago, such moral judgements are culturally and historically specific, rooted in religio-moralistic discourses that frame and underpin idealised notions of the values and purpose of 'proper' relationships between men and women. Since the material basis of heterosexual relationships has been unpacked extensively in critical thinking across feminist, Marxist and post-colonial work, the body of work foregrounding the materiality of sexual relationships in African countries in particular may inadvertently be another form of racialised 'othering' of African sexualities. Researchers in this terrain need to be ever vigilant of their work inadvertently reproducing such discourses. Critiques of transactional relationships further need to be carefully reflexive and more critically aware of the multiplicity and complexities surrounding such exchanges, to consider the ways in which transactional sexual relationships are not simply about economics, to go beyond the 'kneejerk' reaction that transactional relationships are inherently wrong and/or inherently abusive for women in particular.

Notwithstanding the importance of avoiding a reductive approach, it is also clear that certain intersecting inequalities - in particular those built around gender, class, age and geographical location serve to facilitate unequal relationships. These inequalities combine 
on this (and other campuses) to position as potentially vulnerable to inequitable transactional relationships first-year female students, especially those from non-urban, less resourced environments and, as emerges here, students who are not South African citizens. It is important that these specificities, and student understandings of them, are recognised in institutional responses to HIV, coercive sexual practices, gender-based violence, transactional relationships and other expressions of inequality. Thus it remains important to appreciate the complexity of students' lives and backgrounds, of their origins in communities and societies characterised by multiple inequalities structured around unequal access to status, power and resources both nationally and in international context. The findings of this study highlight the complexities and specificities of this particular sub- cultural context of contemporary South African campus life that suggest multiple and diverse forms of resources that may be exchanged for sexual intimacy, not only access to money and material goods. These exchanges of resources and the use of sex as a commodity for exchange by women in particular become a challenge when they are framed by gendered, classed and other inequalities and disparities that undermine agency and that facilitate abusive and exploitative practices.

\section{Acknowledgements}

We acknowledge the students who shared their stories, Elron Fouten for fieldwork, the HIV and AIDS Programme at UWC for initiating the research and the two anonymous reviewers for their helpful guidance.

\section{Note}

1. Apartheid policies of segregation designated this university for those categorized as Coloured. Today, the university continues to serve many of those historically classified as Black in apartheid South Africa but includes a far wider diversity, about 50\% of those historically classified as African as well as students who were classified White and Indian and a growing population of international students, especially from other countries in Africa. Racialised categories continue to have salience in contemporary South Africa and are used officially for the purposes of employment and other equity. 


\section{References}

Adam, M., and M. Mutongi. 2007. Sexual behaviour among Kenyan University Students. J ournal of Arizona-Nevada Academy of Science 39, no. 2: 91- 8.

Bhana, D. and R. Pattman. 2011. Girls want money, boys want virgins: The materiality of love amongst South African township youth in the context of HIV and AIDS. Culture, Health \& Sexuality 13, no. 8: 961- 73 .

Casale, D., and D. Posel. 2005. Women and the economy: How far have we come? Agenda 64: $21-9$.

Clowes, L., T. Shefer, E. Fouten, T. Vergnani, and J. J acobs. 2009. Coercive sexual practices and gender-based violence on a university campus. Agenda 80: 22-32.

Cronan, S. 1973. Marriage. In Radical feminism, ed. A. Koedt, E. Levine, and A. Rapone, 213- 21. New York: Quadrangle.

Crush, J ., and W. Pendleton. 2004. Regionalizing xenophobia?

Citizen attitudes to immigration and refugee policy in Southern Africa, South African Migration Project. IDASA (Institute for Democratic Alternatives for South Africa). http:// www.idasa.org/ media/ uploads/ outputs/ files/ SAMP\%2030.pdf

de Beauvoir, S. 1982. The second sex. Harmondsworth: Penguin [first published 1949].

Dunkle, K.L., R.K. Jewkes, H.C. Brown, G.E. Gray, J.A. McIntyre, and S.D. Harlow. 2004. Transactional sex among women in Soweto, South Africa: Prevalence, risk factors and association with HIV infection. Social Science and Medicine 59: 1581- 92.

Dunkle, K.L., R.K. Jewkes, M. Nduna, N. J ama, J. Levin, Y Sikweyiya, and M.P. Koss. 2007.Transactional sex with casual and main partners among young South African men in the rural Eastern Cape: Prevalence, predictors and associations with gender-based violence. Social Science \& Medicine 65: 1235- 48.

Ergene, T., F. Cok, A. Tumer, and S. Unal. 2005. A controlled-study of preventive effects of peer education and single-session lecturers on HIV/AIDS knowledge and attitudes among university students in Turkey. AIDS Education and Prevention 17, no. 3: 268- 78.

Gould, C., and N. Fick. 2008. Selling sex in Cape Town: Sex work and human trafficking in a South African city. Cape Town: SWEAT/ISS.

Gukurume, S. 2011. Transactional sex and politics of the belly at tertiary educational institutions in the era of HIV and AIDS: A case study of Great Zimbabwe. University and Masvingo Polytechnical Colleage. J ournal of Sustainable Development in Africa 13, no. 3: 178-93.

Hesse-Biber, S., ed. 2007. Handbook of feminist research: Theory and praxis. Thousand Oaks, CA:Sage.

Holland, J., C. Ramazanoglu, S. Scott, S. Sharpe, and R. Thomson. 1991. Pressure, resistance, empowerment: Young women and the negotiation of safer sex. Women Risk and AIDS Project

(WRAP) Paper 6. London:Tufnell Press. 
Hollway, W. 1989. Subjectivity and method in psychology: Gender, meaning and science. London: Sage.

Hunter, M. 2002. The materiality of everyday sex: Thinking beyond prostitution. Africa Studies 61: 99- 120.

Hunter, M. 2009. Providing love: Sex and exchange in twentiethcentury South Africa. In Love in Africa, ed. J. Cole and L. Thomas, 137- 57. Chicago, IL: University of Chicago Press.

Hunter, M. 2010. Love in the time of AIDS: Inequality, gender and rights in South Africa. Pietermaritzburg: University of KwaZulu-Natal Press.

Jungar, K., and E. Oinas. 2004. Preventing HIV? Medical discourses and invisible women. In Re-thinking sexualities in Africa, ed. S. Arnfred, 97 - 114. Uppsala, Sweden: Nordic Africa Institute.

Leclerc-Madlala, S. 2004. Transactional sex and the pursuit of modernity. Social Dynamics 29, no. 2: 1- 21.

Lesch, E., and L. Kruger. 2004. Reflections on the sexual agency of young women in a low-income rural South African community. South African J ournal of Psychology 34, no. 3: 464- 86.

Lindegger, G., and J. Maxwell. 2007. Teenage masculinity: The double bind of conformity to hegemonic standards. In From boys to men: Social constructions of masculinity in contemporary

society, ed. T. Shefer, K. Ratele, A. Strebel, N. Shabalala, and R. Buikema, 94-111. Cape Town: UCT Press.

Maganja, R.K., S. Maman, A. Groves, and J.K. Mbwambo. 2007. Skinning the goat and pulling the load: Transactional sex among the youth in Dar es Salaam, Tanzania. AIDS Care 19, no. 8: 974-81.

Masvawure, T. 2010a. 'I just need to be flashy on campus': Transactional sex at the University of Zimbabwe. Culture, Health and Sexuality 12, no. 8: 857- 70 .

Masvawure, T. 2010b. Low-risk youth? Students, campus life and HIV at a university in Zimbabwe., PhD diss., University of Pretoria. Okin, S.M. 1989. Justice, gender and the family. New York: Basic Books.

Oxlund, B. 2009. Love in Limpopo: Becoming a man in a South African university campus. PhD Series no. 45, Department of Anthropology, University of Copenhagen.

Page, R.M., J .J . Hammermeister, and A. Scanlan. 2000. Everybody's not doing it: Misperceptions of college students' sexual activity. American J ournal of Health Behavior 24, no. 5: 387-94.

Patton, C. 1990. Inventing AIDS. New York: Routledge.

Ramazanoglu, $\mathrm{C}_{i}$, and J. Holland. 2002. Feminist methodology: Challenges and choices. London: Sage.

Ratele, K. 2006. Ruling masculinity and sexuality. Feminist Africa 6: $48-64$. 
Seidel, G. 1993. The competing discourses of HIV/AIDS in subSaharan Africa: Discourses of rights and empowerment versus discourses of control and exclusion. Social Science \& Medicine 36, no. 3: $175-94$.

Seloilwe, E. 2005. Factors that influence the spread of HIV/AIDS among students of the University of Botswana. Journal of the Association of Nurses in AIDS Care 16, no. 3: 3- 10.

Shefer, T., K. Ratele, A. Strebel, and N. Shabalala. 2005. Masculinities in South Africa. Acritical review of contemporary literature on men's sexuality. In Rethinking masculinities, violence and AIDS, ed. D. Gibson and A. Hardon, 73 - 86. Amsterdam: Het Spinhuis.

Shefer, T., and D. Foster. 2009. Heterosex among young South Africans: Research reflections. In The price/the prize: Shaping sexualities in the new South Africa, ed. M. Steyn and M. Van Zyl, 267- 89. Cape Town: HSRC Press.

Shisana O., T. Rehle, L.C. Simbayi, K. Zuma, S. J ooste, V. Pillay-vanWyk, N. Mbelle, J. VanZyl, W. Parker, N.P. Zungu, and S. Pezi, and the SABSSM III Implementation Team. 2009. South African national HIV prevalence, incidence, behaviour and communication survey 2008: A turning tide among teenagers? Cape Town: HSRC Press.

Ulin, P.R. 1992. African women and AIDS: Negotiating behavioral change. Social Science \& Medicine 34: 63- 73.

Valji, N. 1993. Creating the nation: The rise of violent xenophobia in the New South Africa. Masters thesis, University of York. Centre for the Study of Violence and Reconciliation. http:// www.cs vr.org.za/ docs/ foreigners/ riseofviolent.pdf

Varga, C. 1997. The condom conundrum: Barriers to condom use among commercial sex workers in Durban, South Africa. African J ournal of Reproductive Health 1, no. 1: 74-88.

Waldby, C., S, Kippax, and J . Crauford. 1993. Cordon sanitaire: 'clean' and 'unclean' women in the AIDS discourse of young heterosexual men. In AID : facing the second decade, ed. P. Aggleton, P. Davies, and G. Hart, 29-39. London: Falmer Préss.

Wamoyi, J., D. Wight, M. Plummer, G.H. Mshana, and D. Ross. 2010. Transactional sex amongst young people in rural northern Tanzania: An ethnography of young women's motivations and negotiation. Reproductive Health 7, no. 2, Reproductive Health J ournal. http:/ / www.reproductive-health-journal.com/ content/ 7/ 1/2

Wood, K., and D. Foster. 1995. 'Being the type of lover ... '.: Gender differentiated reasons for non- use of condoms by sexually active heterosexual students. Psychology in Society 20: 13- 35. 